\title{
The relevance of social interactions on housing satisfaction
}

\author{
Esperanza Vera-Toscano $\cdot$ Victoria Ateca-Amestoy
}

Received: 23 February 2007/Accepted: 5 March 2007/Published online: 31 March 2007

(C) Springer Science+Business Media B.V. 2007

\begin{abstract}
For most individuals, housing is the largest consumption and investment item of their lifetime and, as a result, housing satisfaction is an important component of their quality of life. The purpose of this paper then is to investigate the determinants of individual housing satisfaction as a particular domain of satisfaction with life as a whole, examining the effects of individual and household attributes (predictive), housing characteristics (hedonic), and more importantly, of social interactions originated in one's residential neighbourhood. To do so, we model housing as a composite commodity that satisfies dwelling needs, as well as other intangibles such as familiar relationships and socio-status aspects. We use the Survey of Living Conditions and Poverty (Spain). Specifically, using a self-reported measure of housing satisfaction, we estimate ordered probit models searching for the empirical specification that provides the best fit accounting for divergences driven by aspirations defined in the own household (internal norm), and by social comparisons (peer-effect or external norm).
\end{abstract}

Keywords Subjective well-being $\cdot$ Housing $\cdot$ Peer-effects $\cdot$ Ordered probit

\section{Introduction}

Housing is a composite commodity (in the sense of Gary Becker) that fulfils several human needs. The major need is dwelling, ${ }^{1}$ but we can also argue that having a social space to

1 In some societies, this individuals' need for housing is considered to be a basic one, so it is protected by constitutional arrangements such as in the Spanish Constitution (art. 47).

E. Vera-Toscano $(\varangle) \cdot$ V. Ateca-Amestoy Institute for Advanced Social Studies, National Higher Research Council (IESA-CSIC), Campo Santo de los Mártires, 7, Cordoba 14004, Spain

e-mail: evera@iesaa.csic.es

V. Ateca-Amestoy

FAE II, University of the Basque Country, Bilbao, Spain 
interact and socialize with family and friends, or to be able to reach a desired social status, might be some reasons for which individuals demand some housing services. Thus, from a social point of view, housing is more than a dwelling unit and its objective characteristics, since it also provides security, privacy, neighbourhood and social relations, status, community facilities and services, access to jobs and control over the environment. The complexity of the concept entails that being "ill-housed", could mean deprivation along any of these dimensions. (Pynoos et al. cited in Foley 1980).

Once we agree on the necessity of housing, the diversity in individual circumstancesconstraints - and technological factors-household production functions and economies of scale particularly relevant for the production of this commodity-lead to big heterogeneity in the revealed behaviour, that is, the demand for housing services. In the same way, the derived level of housing satisfaction (an elicited valuation) once the optimal housing choice has been made and implemented (objective revealed preference), is also likely to vary from one individual to another.

Based on the utility theory, we assume that individuals will do their best, given their particular housing situation, to maximize their utility. For that reason, the level of satisfaction derived from a given housing situation will ultimately be an important determinant of individual well-being. As argued by Diener and Biswas-Diener (2002) for financial satisfaction, housing satisfaction can also be seen as a "mediator" of individual happiness or well-being. ${ }^{2}$ Interest in satisfaction with different aspects of life as mediators to explain individuals' happiness or quality of life started some decades ago as alternative measures to objective quality of life indicators. For instance, a survey in the United States (Campbell et al. 1976), although rather dated, found that for most people housing satisfaction ranks fourth after financial situation, leisure activities and, job status on the perceived and actual importance of different sources of overall satisfaction in everyday life, followed by friendship, family life, marriage and health. ${ }^{3}$ More recently, Van Praag et al. (2003) have claimed and studied that happiness as a whole can be seen as an aggregate concept, which can be unfolded into individual satisfaction with different domains of life such as health, job, finances and, of course, housing situation.

Nonetheless, research on individuals' housing satisfaction as a specific domain of individual happiness has been very scarce among economists. Authors such as Van Praag and Ferrer-i-Carbonell (2004) proposed a double approach to the configuration of housing satisfaction, explaining it by: (1) a precise description of the house in which the respondent is living (hedonic approach), following Lancaster's approach to product characteristics; and (2) with reference to the specific characteristics of that individual (predictive). Alternatively, Lu (1999) studied the effects of a combination of housing, neighbourhood, and household characteristics on individuals' satisfaction with dwelling. More recently, Díaz-Serrano (2005) performs an analysis of the determinants of housing satisfaction, the effect of housing satisfaction on housing mobility, and the potential different attitude and behaviour with respect to the tenure regime (owners versus renters). However, no research to our knowledge has been done to investigate the relevance of social interactions on housing satisfaction. The rationale for this proposal is that individuals belong to social groups, and this belonging is likely to have an impact on their behaviour (objective

\footnotetext{
${ }^{2}$ Happiness, quality of life and well-being are used interchangeably.

${ }^{3}$ Using our data and calculating relative importance Pratt indexes to measure the weight that different dimensions have on overall life satisfaction, housing satisfaction is the second most important domain, once we control for the influence of other domain satisfactions, namely: environmental, financial (which ranks first), leisure, health and job.
} 
outcome in the sense of housing services demand-objective revealed preferences), as well as on their level of satisfaction with that behaviour (subjective outcome as valuation/ divergence with aspirations).

Housing satisfaction is an elicit variable, expressing the degree of content that a given housing situation provides to an individual (subjective outcome). Although, as an attitude, the unobserved indirect utility reached for a given housing situation is a "latent variable"; however, the housing satisfaction variable (measured through direct questions about their level of housing satisfaction) captures the valuation of how the housing services need is individually satisfied, and can be used as an ordinal measure of true housing satisfaction so that higher reported housing satisfaction is equivalent to higher true housing satisfaction. Answers to these questions provide meaningful results at ordinal level (Ferrer-i-Carbonell 2002; Kahneman et al. 1999; Sen 1999). Accordingly, considering a subjective approach to the measure of housing satisfaction offers a psychologically and sociologically sounder way to study individual behaviour (Frey et al. 2003).

The purpose of this paper then is to investigate the determinants of individual housing satisfaction as a particular domain of satisfaction with life as a whole, examining the effects of housing characteristics (hedonic), individual and household characteristics (predictive), and more importantly, the effect of social interactions originated in one's residential neighbourhood on the housing satisfaction domain. This is made possible with a unique dataset (Survey on Living Conditions and Poverty for Andalucia, Spain) that includes individual data on reported housing satisfaction, as well as detailed information on dwelling conditions and individual's characteristics.

This paper contributes the existing literature in a number of ways. First, we investigate the effect of social interactions understood as contextual effects based on location criteria ("peer-effect or external norm"). Within this contribution we also study the relevance of social capital (measured as informal contacts with neighbours) so as to accommodate the intensity of these contextual effects. Second, the characteristics of the Spanish society in relation to housing market conditions, with a big percentage of owners (above EU average, even among the bottom $20 \%$ of the income distribution) and a steady price increase may be of special interest to test the hypothesis that owners do enjoy greater housing satisfaction than renters (other things being equal). Besides, studies on housing satisfaction very rarely considered, to our knowledge, the price of the services derived from the dwelling (either rented or owned) as a potential explanatory variable. It could be due to the lack of reliable information of these prices. We try to overcome this limit by bringing into the analysis the information contained in another statistical source. In this research, we perform hedonic regressions with the information contained in another dataset: the Encuesta Continua de Presupuestos Familiares from the National Statistics Institute of Spain (Instituto Nacional de Estadística 2005). ${ }^{4}$ The purpose is to bring those imputed (predicted) prices in the regression as an explanatory variable for housing satisfaction. Last, individuals' subjective evaluations of their housing determine the way they respond to residential environment and form the basis of demands for public action. Therefore, there is no doubt on the policy implications of this study as public housing policies are likely to have an impact on individual happiness through housing satisfaction. Understanding how individuals form their housing satisfaction can be used to design more effective housing programs and avoid problems that may result if the perceptions of policy makers do not coincide with those of residents.

\footnotetext{
${ }^{4}$ We use data for 2003 in order to get some accurate measure of the price of services.
} 
The rest of the paper proceeds as follows. Section 2 reviews the housing satisfaction concept and presents the potential effects of social interactions on this well-being domain. In Sect. 3, we present the data, the hypotheses that we want to test, and the model that we estimate. Section 4 discusses the results for the housing satisfaction model. Section 5 presents overall conclusions.

\section{Housing satisfaction and social interactions: background and context}

Housing satisfaction is a complex cognitive construct, and several attempts have been made to conceptualize it from disciplines other than Economics (Sociology, Psychology, Planning, or Geography). Overall, it is worth noting that theories of housing satisfaction all centre around the notion that housing satisfaction measures the difference between households' actual and desired (or aspired-to) housing and neighbourhood situations (Galster 1987; Galster and Hesser 1981; Lu 1999). Therefore, individuals make judgements about residential conditions based on their needs and aspirations. Satisfaction with one's residential situation indicates the absence of complaints and a high degree of agreement between actual and desired situations. On the other hand, incongruence between their actual housing and needed conditions may lead to dissatisfaction.

Morris and Winter $(1975,1978)$ introduced the notion of "housing deficit" to conceptualize residential (dis)satisfaction. In their housing adjustment model of residential mobility, they theorize that individuals judge their housing conditions according to normatively defined norms, including both family and personal norms and aspiration (internal norm), which account to households' own standards for housing, and cultural norms, which are dictated by societal standards or rules for life conditions (this idea equals what we called the external norm or peer-effect in financial satisfaction-see Vera-Toscano et al. 2006).

In this sense, Rossi (1955) posits that changing housing needs and aspirations as households progress through different life-cycle stages often place households out of conformity with their housing and neighbourhood situations. The "lack of fit" between their current and desired housing needs creates stress or dissatisfaction through migration or remodelling, which brings a family's housing into adjustment with its housing needs subject to the constraints posed by their financial resources and by the information regarding alternative adaptation opportunities.

Moreover, there is little doubt that human beings are socially influenced by many means. When discussing social interactions, we refer to interdependencies between individual decisions or behaviour and the decisions and characteristics of others within a common group (which will be defined on a spatial basis-neighbourhood-in our case of study). As argued by Brock and Durlauf (2003), in virtually any economic model describing individual behaviour, the decisions of one individual will be influenced by the behaviour and characteristics of others.

Following Manski (1993), who adopts the term "social interactions" from the sociology literature, one can think of an agent's interactions with her neighbourhood as being composed of two factors: contextual and endogenous. The first (contextual) refers to those factors that are group specific and based on characteristics of the group members. The second (endogenous) refers to how agents are affected by the contemporaneous behavioural choices of group members. These alternative factors are 
illustrated in the context of residential neighbourhoods, which represent an important leading case in the social interactions literature (see for example, Brock and Durlauf 2003; Ioannides and Zabel 2003). In summary, there exists an increasing recognition in economics, that social interactions do play a major role in explaining a range of individual behaviours, as well as the individual's valuation of both the decision and the resulting outcome.

The impact on individual behaviour itself (objective revealed preference) of these social interactions refers to the influence of solidly established social norms on that behaviour. Thus, if we look, for example, to unemployment attitudes (Clark 2003), we can argue that the psychological experience of unemployment is tempered by the labour market status of those with whom the individual is in close contact, as models of comparisons or norms would imply. This relationship could also help to explain objective outcomes such as the polarization of work between households, unemployment hysteresis, and the existence of poverty traps or the duration of unemployment. More related to our interest, social interactions can help to explain neighbourhood formation (Brock and Durlauf 2003).

In the same way, there is little doubt that individuals' satisfaction (elicited valuation) with a given behaviour (objective revealed preference) will also depend on what one achieves in relative terms that is, compared to other individuals. Veblen (1899) coined the notion of "conspicuous consumption", as serving to impress other people. Another types of non-functional demands include the "bandwagon effect', when individuals consume a good because a large proportion of the society does it. In these cases, the good serves the purpose of social belonging or status defining.

The reference group (relevant "others") could include all members of a society, or a subgroup of them, such as individuals living in the same neighbourhood or peers having the same education level. There has been both theoretical and empirical work on the choice and importance of the reference group for individuals' well-being (Falk and Knell 2000; Ferrer-i-Carbonell 2002b). Empirical evidence can be found in research on both financial and job satisfaction. On the former, it is income in relative terms what provides satisfaction (in an attempt of keeping up with the Joneses). Thus, the presence of richer people in our reference group imposes a negative externality, while the opposite does not hold (Ferrer-i-Carbonell and Fritjers 2004; Luttmer 2005; Vera-Toscano et al. 2006). For the later, the impact of own employment status once a social norm in the reference group operates, has an impact on well-being (Clark 2003).

In addition to what has been written so far on the effects of social interactions on housing satisfaction, it may be important to further consider the impact of individual's social capital as a measure of the intensity of these social interactions. The relevance of interpersonal dependence may be shaped by individual's social capital. We understand social capital as an individual's resource built from her integration in social networks. Trust is one of the most studied approaches to individual's social capital measurement, while another frequent approach considers social interactions. At a community level, Putnam (1993) argues that economic development is closely related to the importance of social capital since the presence of social networks increases trust, decreases transaction costs and makes information and innovation more fluent. Analysis of this social capital concept may certainly offer new insights into the determinants of housing satisfaction. 


\section{Data, hypotheses and empirical specification}

The dataset used for our empirical study is derived from the Survey on Living Conditions and Poverty in Andalucía. It consists on a household survey conducted by the Institute of Advanced Social Studies of Andalucía (IESA-CSIC) in Spain with funding from the Department of Social Affairs of the Andalucian Regional Government. The sample consists of 6,000 personal interviews containing information for 6,000 households and around 21,000 individuals (since for some items, the respondent is asked to provide information of all household members). The target population was all people living in Andalucía aged over 18. The survey was designed to capture the well-being of individuals and household. From this data, a sample was drawn of 4,285 questionnaires respondents that provided complete information on the variables considered in our study.

The analysis now focuses on the measurement of individual housing satisfaction and the identification of its determinants. We assume that housing satisfaction $H S_{i}$, as an observable variable is related to the utility that the current housing situation provides to the agent $\left(H S_{i}^{*}\right)$, which is unobservable. We then ask individuals how they feel about their current housing situation. The answer to this question takes discrete values from 1 (very unhappy) to 7 (very happy) and, as already mentioned, we assume that such an answer is meaningful and comparable between individuals (Clark 1997; Clark and Oswald 1994; Ferrer-i-Carbonell 2002a) providing plausible results. Since HS is an ordered categorical variable, we estimate the usual Ordered Probit model (Greene 1990).

Furthermore and very important, from the individual decision-making point of view, we assume that optimal housing choice has already been made at some past time, previous to the moment of the survey (maximization of utility subject to constraints, leading to optimal allocation of resources to competing purposes). By assuming that the optimal choice is the implemented one, which is being valued, we can discard from our model the endogenous effects driven by social interactions (see Ioannides and Zabel 2003 for an empirical study on these endogenous effects). Let's assume that even if the optimal individual decision might have been determined by the influence of relevant others characteristics (such as the tenure regime of the peers), that decision was taken in a previous time, and thus the only social interaction effect would be a contextual effect in terms of comparison of outcomes.

\subsection{Definition of regressors and hypotheses}

The selection of explanatory variables for this study is guided by past research on housing satisfaction, the purpose of this current research and data availability (see Table 1 for a summary of the explanatory variables). Four groups of variables are considered. The first group includes variables representing individual and household attributes, such as age, sex, educational attainment and household income. Household type is also included in the analysis to control for possible differences in the assessment of same housing conditions by individuals with different household background. Thus, being older, having higher income or having a smaller family all have been related to more housing satisfaction (Campbell et al. 1976). Empirical evidence also concludes that the education effect is negative.

\footnotetext{
5 The sample is drawn using a stratified, multi-stage design using probability sampling. The principal stratification of the sample takes place by poverty levels, gender and age. Primary sampling units were selected in different ways depending upon the relevant size of municipalities combined with census units.
} 
Table 1 Summary of the explanatory variables

Variable labels Description

1. Individual and household attributes

Age

Age of the reference person (in years), five different categories were created: $1 .<35,2$. 35-44, 3. 45-54 (reference category), 4. 55-64 and 5. $\geq 65$.

Sex

1 if male, 0 if female

Education attainment

1 if no studies (reference category), 2 if primary school, 3 if secondary schooling, 4 if University degree

Household type

1 if single person household, 2 if married couples without children, 3 if married couples with children (reference category), 4 if single parent household, 5 other household types.

Household income

In logarithmic form (imputed monthly household income)

2. Housing, neighbourhood and locational variables

Tenure

Public Housing

Property value

Housing adequacy/quality

Room stress

Province

Rural/urban

3. Individuals' perceptions of their neighbourhood

Bother

Services

1 if something about neighbourhood is bothersome, 0 otherwise

\section{The effect of social interactions}

Tenure of the reference group For the reference group (censal units) we calculate the mode of ownership and create three variables:

1. tenureabv which equals 1 if you own in a modal renting neighbourhood and 0 otherwise.

2. tenureeq equals 1 if you live in a neighbourhood similar to your ownership status and 0 otherwise.

3. tenurebel equals 1 if you rent in a model owning neighbourhood and 0 otherwise.

Public/private housing of the reference group

For the reference group we calculate the mode of public housing and create three variables:

1. protecabv which equals 1 if you live in private housing in a mostly public housing neighbourhood and 0 otherwise.

2. proteceq equals 1 if you live in a neighbourhood similar to your private/ public housing status and 0 otherwise.

3. protecbel equals 1 if you live in public housing in a mostly private housing neighbourhood and 0 otherwise.

Property value of the reference For the reference group we calculate the mean of house price and create group pricedif $^{=} \ln \left(\right.$ hprice/hprice $\left._{G}\right)$ where hprice $_{G}$ is the mean price of the neighbourhood. After taking logs, pricedif takes positive values for agents above mean and negative for those below. 
Table 1 continued

Variable labels $\begin{aligned} & \text { Description } \\ & \text { Looking at pricedif we create up to four different dummy variables as } \\ & \text { follows: } \\ & \text { If pricedif is positive, meaning that individual household income are } \\ & \text { larger than the reference group CTM income we have: } \\ & \text { 1. veryrich equals } 1 \text { for those with the largest positive pricedif (up to } \\ & \text { 50\% of the observations) and } 0 \text { otherwise. } \\ & \text { 2. rich equals } 1 \text { for the remaining observations with a positive pricedif } \\ & \text { and } 0 \text { otherwise. } \\ & \text { If pricedif is negative, meaning that individual household income is } \\ & \text { smaller than the reference group CTM income we have: } \\ & \text { 3. poor equals } 1 \text { for those with the smallest negative pricedif (up to } \\ & \text { 50\% of the observations) and } 0 \text { otherwise. } \\ & \text { 4. verypoor equals } 1 \text { for the remaining observations with a negative } \\ & \text { pricedif and } 0 \text { otherwise. } \\ & \text { Each or these dummies is treated as an indicator function that shapes the } \\ & \text { presence our pricedif variable, allowing for non-linear effect of this } \\ & \text { difference depending on both sign and magnitude. The } 4 \text { resulting } \\ & \text { variables are called "hpveryrich", "hprich", "hppoor", } \\ & \text { "hpverypoor". } \\ & \text { This is an "Informal social capital" measure. It takes information from } \\ & \text { the question "how often do you meet with neighbours?". The variable } \\ & \text { equals } 1 \text { if regular contacts (daily, weekly and/or monthly) and } 0 \\ & \text { otherwise. }\end{aligned}$
Social capital

Higher-educated people are more critical of their housing conditions or have higher expectations that cannot be met. In addition, previous empirical studies show that males seem to be less satisfied with their housing than are females. (Van Praag and Ferrer-iCarbonell 2004). We find of particular interest to contrast some hypotheses for age and gender effects. For the first one, there is evidence that the increased price of housing may lead to younger cohorts of the population to be outcasted, since they are entrants in a market in which the relative initial effort to acquire a house (if the tenure decision leads to an optimal purchasing choice) is high and continuously increasing. For the gender effects, we may find evidence of a division of roles in the household for Andalucía, since it is referred that housing activities are mostly allocated to female parts of the family.

The second group of variables is comprised of housing and neighbourhood conditions and locational variables. Tenure, whether the house is public housing and property value are included. Home owners, are almost always more satisfied with their home and neighbours (in fact, with their lifes in general) than are renters (Rohe and Basolo 1997). Several works have stated the positive outcomes related to ownership. It increases social capital, since individuals are more likely to invest in the relationships with their permanent neighbours. Moreover, since homeowners have a larger financial stake in their neighbourhoods, they are more concerned by the amenities publicly provided (such as schooling, health services, and so on). It also produces other positive externalities (Bajari et al. 2005; Di Pasquale and Glaeser 1999; Green and White 1997). However, ownership also limits mobility which may impose costs, namely by increasing unemployment (Oswald 1999). The argument is that an economy's "natural rate" of unemployment depends on the ease with which its citizens can move around to find jobs. Fluid societies have efficient 
economies. The housing market is likely to have an influence on the degree of labour mobility in the following way: by making expensive to change location, high levels of home-ownership foster spatial mis-match between works.

Regarding the effect of the property value on individuals' well-being, for the USA case, Bajari et al. in a recent contribution discuss the impact of the increase of housing prices. While there is a positive effect since price appreciation strengthens the balance sheets for existing homeowners, there is also a negative effect as "household in the lower tail of the income distribution are now less able to afford housing that they were a decade ago'. This same process is happening for Spain. The effect on household balance sheets is also considered by Banco de España (mainly Bover 2004, 2005). The magnitude of this effect will depend on the degree of borrowing (given a fixed mortgage in the "liability", there is an increase in the nominal value of the housing "asset"). The impact of these changes on individual well-being is still to be assessed. As already mentioned in Section 1, no research to our knowledge, has considered the price of the services derived from the dwelling (either rented or owned) as a potential explanatory variable. In our research we perform hedonic regressions with information contained in another dataset, the "Encuesta Continua de Presupuestos Familiares" from the National Statistics Institute of Spain and bring the imputed (predicted) prices in the regression as an explanatory variable for housing satisfaction (results from the hedonic regression are available from the authors upon request).

In other matter, previous studies have shown that housing quality problems often have significant effects on dwelling satisfaction. Therefore, a variable indicating housing quality as perceived by the individuals is also introduced in our analysis. The variable includes five levels: very adequate, adequate, normal, moderately inadequate and severely inadequate. This self-reported measured of housing quality may have its limitations but it does indicate the overall quality of housing. In addition, a room stress index is created. The index is defined as the ratio between the size of the house (in squared meters) and the number of people living in the household. Thus, the index is used to measure the relative scarcity or abundance of housing space. By definition, large values of the ratio indicate that more space is available than required by the household. Four dummy variables have been introduced to control for the physical space available in the household. The locational variables are included in the model to differentiate the eight provinces and to distinguish between individuals residing in rural, semi-rural and urban areas.

The combination of the former two sets of regressors, we are able to model how adequate the objective characteristics of the housing are for the household that is being surveyed. We will call this effect the internal norm.

The third set of regressors includes a few variables regarding individuals' perceptions of their neighbourhood. Given the close relationship between housing and neighbourhood

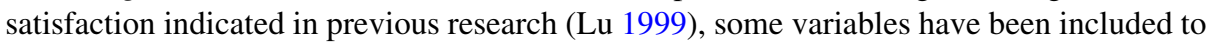
control whether individuals perceive something bothersome about their neighbourhood, which may include such problems as noise, crime, traffic, or litter. Equally, dummies to control for the presence of certain public services in the neighbourhood, as a proxy for neighbourhood quality have also been included.

The fourth and last group of regressors includes the impact of social interactions and the comparison with neighbours. We have already mentioned that when modelling subjective wellbeing, it is essentially to take into account that satisfaction judgements are comparison driven. Each person always make this evaluation by comparing her situation with her aspiration, potentially determined by the outcome of some relevant others. Following an empirical model estimated by Ioannides and Zabel (2003), we investigate to what extent nearest (in a geographical sense) housing characteristics are used for 
comparison. We define reference groups by "censal units", which corresponds with a building block. Thus, we investigate the divergence among certain individual housing characteristics and modal or mean housing characteristics of the relevant others. Specifically, we use the mode for tenure and public housing and the mean for property value. This social interaction effect will be referred as the external norm or peer-effect. We hypothesize that comparisons are upwards looking since richer people, or people holding a home of better quality impose a negative externality.

Lastly, we test for the effect of social capital through group comparisons assuming that those that interact more with their neighbourhoods and relatives are potentially more exposed to the negative effect of social comparisons. By including in our regression a measure of social capital (informal contact with neighbours), we can test for the effect of social capital.

\subsection{Empirical specification}

Given the ordinal nature of our dependent variable, and further assuming that the underlying variable (utility as a latent variable) depends in a linear way on the set of regressors and error term (which in turns is assumed to be normally distributed: $\varepsilon_{i} \rightarrow N(0,1)$, we propose to estimate our housing satisfaction model by means of an ordered probit (Greene 1990). In the structural form of the model, the real axis is divided in intervals $\left(-\infty, \mu_{1}\right], \ldots,\left(\mu_{7}, \infty\right)$, such that the latent variable $H S^{*} H S^{*} \in\left(\mu_{k}, \mu_{k+1}\right]$ if $H S=k$.

We mentioned earlier that from the individual decision making point of view, we assume that the optimal choice has been made at some past time, previous to the moment of the survey (maximization of utility subject to constraints, leading to optimal allocation of resources to competing purposes). Therefore, the individual will value her housing situation taking into account the characteristics of her home and neighbourhood, how suitable that home is to fulfil her dwelling needs, as well as some social interaction effects such that the empirical specification stays as follows,

$$
H S_{i}^{*}=f\left(X_{i}, H_{i}, N_{i}, \bar{H}_{j i}, S C_{i}\right)
$$

where $X_{i}$ refers to the vector of individual socio-economic and household composition variables; and $H_{i}$ and $N_{i}$ include house and neighbourhood related variables, respectively, while $\bar{H}_{j i}$ is the vector which contains the divergence between the individual housing attributes and the modal or means ones of the reference group (neighbourhood-cluster in our analysis). Lastly, $S C_{i}$ contains the informal social capital variable.

The decision on which variables to include is ultimately based on exploratory analysis and data availability. Table 2 reports the means and standard errors of the variables used in the regression.

\section{Results}

The next stage of the analysis examines the factors that affect individual housing satisfaction using ordered probit estimations. Results are presented in the Table 3. If we first consider individual attributes, in line with previous empirical findings, having higher income or a smaller family is related to more housing satisfaction. Furthermore, the larger individual's education level the significantly more satisfied they are with their housing 
Table 2 Sample statistics

\begin{tabular}{|c|c|c|}
\hline Variables & $\%$ (means if counts) & Standard errors \\
\hline \multicolumn{3}{|c|}{ Dependent variable: housing satisfaction } \\
\hline Very unsatisfied & 0.0112 & 0.002 \\
\hline Unsatisfied & 0.0122 & 0.001 \\
\hline Pretty unsatisfied & 0.0328 & 0.004 \\
\hline Not unsatisfied, nor satisfied & 0.0453 & 0.005 \\
\hline Pretty satisfied & 0.2321 & 0.022 \\
\hline Satisfied & 0.4199 & 0.016 \\
\hline Very satisfied & 0.2462 & 0.019 \\
\hline \multicolumn{3}{|c|}{ Objective individual characteristics } \\
\hline Age $(<35)$ & 0.3063 & 0.009 \\
\hline Age (35-45) & 0.1893 & 0.007 \\
\hline Age (46-55) & 0.1242 & 0.007 \\
\hline Age (56-65) & 0.1459 & 0.010 \\
\hline Age $(65+)$ & 0.2341 & 0.010 \\
\hline Male & 0.4974 & 0.008 \\
\hline No studies & 0.2938 & 0.015 \\
\hline Primary schooling & 0.3127 & 0.018 \\
\hline Secondary education & 0.2299 & 0.013 \\
\hline University level & 0.1521 & 0.016 \\
\hline Household Income (ln) & 1094.75 & 793.39 \\
\hline Living alone & 0.1696 & 0.011 \\
\hline Living with couple & 0.1854 & 0.009 \\
\hline Nuclear family & 0.4779 & 0.014 \\
\hline Lone parents & 0.0569 & 0.005 \\
\hline Other household types & 0.1099 & 0.007 \\
\hline \multicolumn{3}{|c|}{ Housing, neighborhood and locational characteristics } \\
\hline Tenure (owner) & 0.8804 & 0.012 \\
\hline Public housing & 0.1552 & 0.022 \\
\hline Overcrowded & 0.0127 & 0.002 \\
\hline Narrowness & 0.1487 & 0.012 \\
\hline Normal & 0.2392 & 0.012 \\
\hline Comfort & 0.5992 & 0.016 \\
\hline Very adequate & 0.2062 & 0.015 \\
\hline Adequate & 0.6784 & 0.018 \\
\hline Normal & 0.0846 & 0.007 \\
\hline Moderately inadequate & 0.0259 & 0.004 \\
\hline Severely inadequate & 0.0045 & 0.001 \\
\hline Hedonic House Price & 2798.81 & 1030.45 \\
\hline Rural & 0.4622 & 0.028 \\
\hline Semi-rural & 0.1795 & 0.019 \\
\hline Urban & 0.3581 & 0.027 \\
\hline Almería & 0.0844 & 0.013 \\
\hline Cádiz & 0.1466 & 0.025 \\
\hline
\end{tabular}


Table 2 continued

\begin{tabular}{|c|c|c|}
\hline Variables & $\%$ (means if counts) & Standard errors \\
\hline Córdoba & 0.1136 & 0.017 \\
\hline Granada & 0.1138 & 0.019 \\
\hline Huelva & 0.0606 & 0.012 \\
\hline Jaén & 0.0841 & 0.013 \\
\hline Málaga & 0.1792 & 0.027 \\
\hline Sevilla & 0.2174 & 0.040 \\
\hline Problems in neighborhood with: crime & 0.1712 & 0.012 \\
\hline Drugs & 0.1641 & 0.011 \\
\hline Begging & 0.0835 & 0.010 \\
\hline Alcoholism & 0.0824 & 0.008 \\
\hline Fights & 0.0727 & 0.007 \\
\hline Pollution & 0.0745 & 0.009 \\
\hline Access to the neigh (roads, lights, etc.) & 0.0764 & 0.008 \\
\hline Noise & 0.1414 & 0.012 \\
\hline Dirty streets & 0.1218 & 0.011 \\
\hline \multicolumn{3}{|l|}{ Presence of public services in neighbourhood } \\
\hline Health centres & 0.6187 & 0.026 \\
\hline Buses & 0.6880 & 0.023 \\
\hline Banks & 0.8092 & 0.023 \\
\hline Pre-schools & 0.5500 & 0.021 \\
\hline Primary schools & 0.7463 & 0.026 \\
\hline High schools & 0.6547 & 0.028 \\
\hline Green areas & 0.4263 & 0.027 \\
\hline \multicolumn{3}{|l|}{ Social capital } \\
\hline Has daily, weekly contact with neighbours & 0.3065 & 0.021 \\
\hline
\end{tabular}

compared to individuals with no studies. Contrary to previous expectations, this result regarding education may be due to the high correlation that still persists in Andalucía between the level of education and the family income, especially if we take into account the large proportion of individuals with no studies $(29.3 \%)$ or only primary studies (31.2\%). However, no significant results have been found for age or gender once other variables are controlled for.

Interesting results can also be brought from the effect of housing, neighbourhood and locational characteristics. Although descriptive empirical results with our data support the idea that homeowners tend to be more satisfied with their housing than renters (see Table 4), results are not significant when controlling for other variables. There seem to be then other housing attributes that more significantly explain individuals' housing satisfaction variance, namely: property value, housing adequacy and available house space. Thus, property value is positively related to housing satisfaction. The higher the property value, the more likely individual are satisfied. This reflects that for existing owners, housing is clearly more than a consumption good. As housing prices increase, the current property value is seen as an investment since given a fixed mortgage in the "liability", there is an increase in the nominal value of the housing "asset'. The interpretation for 
Table 3 Ordered probit regression: individual's housing satisfaction

\begin{tabular}{lc}
\hline Variables & $\hat{\beta}$ \\
\hline
\end{tabular}

Individual attributes

Age $(<35)$

$-0.097$

Age (35-44)

$-0.047$

Age (55-64)

0.093

Age (65+)

0.147

Male

0.059

Primary schooling

0.100

Secondary education

$0.228 * *$

University level

$0.290 * *$

Household Income (ln)

$0.212 * * *$

Living alone

Couple

$0.202 *$

Lone parents

$-0.046$

Other household types

Housing, neighbourhood and locational characteristics

Tenure (owner)

Public housing

Hedonic house price (ln)

Severely inadequate

$-1.133 * * *$

Moderately inadequate

$-0.261$

Adequate

Very adequate

$1.114 * * *$

Overcrowded

$-0.524 * *$

Narrowness

$-0.077$

Normal

0.081

Almería

$-0.146$

Cádiz

0.160

Córdoba

$-0.137$

Granada

$-0.093$

Huelva

$-0.009$

Jaén

0.241

Málaga

$-0.206$

Rural

Urban

0.195

Problems in neighbourhood with:

Crime

Drugs

Pollution

Access to the neigh. (roads, lights, etc.)

Noise

Dirty streets

Presence of public services in neighbourhood:

Health Centres 
Table 3 continued

\begin{tabular}{|c|c|}
\hline Variables & $\hat{\beta}$ \\
\hline Buses & -0.086 \\
\hline Banks & 0.011 \\
\hline Pre-schools & -0.026 \\
\hline Primary schools & 0.113 \\
\hline High schools & 0.033 \\
\hline Green areas & $0.171 * *$ \\
\hline \multicolumn{2}{|l|}{ Social interactions and comparison to neighbours } \\
\hline You own in a renting neighbourhood & -0.171 \\
\hline You rent in a tenure neighbourhood & $-0.396^{* *}$ \\
\hline Public housing in a non-public housing neighbourhood & 0.196 \\
\hline Private housing in a public housing neighbourhood & $-0.298 *$ \\
\hline Very expensive house compared to neighbours (ln mean) & -0.166 \\
\hline Expensive house compared to neighbours (ln mean) & 1.439 \\
\hline Less expensive house compared to neighbours (ln mean) & -0.035 \\
\hline Very cheap house compared to neighbours (ln mean) & -0.269 \\
\hline Has daily, weekly contact with neighbours & -0.013 \\
\hline$\hat{\gamma}_{1}$ & $5.064 *$ \\
\hline$\hat{\gamma}_{2}$ & $5.443 * *$ \\
\hline$\hat{\gamma}_{3}$ & $5.964 * *$ \\
\hline$\hat{\gamma}_{4}$ & $6.391 * *$ \\
\hline$\hat{\gamma}_{5}$ & $7.355^{* * *}$ \\
\hline$\hat{\gamma}_{6}$ & $8.638 * * *$ \\
\hline Sample size $(N)$ & 4,285 \\
\hline Log pseudo-likelihood & $-5,723.85$ \\
\hline Pseudo- $R^{2}$ & 10.24 \\
\hline
\end{tabular}

Omitted categories: No studies, couples, Holgura en el room stress index que divide los metros cuadrados por el número de personas en la casa. Habitat semi-rural, Sevilla, the omitted categories for the diverngences are the equivalente between individual and mean or modal characteristics of the neighbourhood. Estado de conservación regular

Legend: $* p<.1 ; * * p<.05 ; * * * p<.01$

renters could be that we will assume that high renting price (brought by means of the imputed value of annual housing services) reduces disposable income. This result of course does not imply that individuals prefer to spend more on housing, rather, it may reflects the fact that in general, high rent is associated with better quality housing. Further, housing adequacy (understood as quality) is positively associated with satisfaction. Lastly, the space available in the house has a significant effect on residents' dwelling satisfaction as the smaller the house the greater the level of dissatisfaction.

Locational and neighbourhood characteristics also have some explanatory power when studying housing satisfaction. Thus, rural resident are more satisfied with their housing (weak significance). This finding supports sociologists' long-held belief that the different types of communities one lives in affect attitudes (Burgess 1925). Individuals seem to consider the intangibles associated with various communities, such as rural or urban areas, when evaluating their house as a place to live. Further, the effect of bothersome factors 
Table 4 Survey proportions estimation

\begin{tabular}{|c|c|c|c|c|c|c|}
\hline \multirow[t]{2}{*}{ Housing satisfaction } & \multicolumn{3}{|c|}{ If owner } & \multicolumn{3}{|c|}{ If renter } \\
\hline & Count & Proportion (\%) & Std. Error & Count & Proportion (\%) & Std. Error \\
\hline Very unsatisfied & 48 & 0.7618 & 0.001881 & 41 & 3.5776 & 0.009390 \\
\hline Unsatisfied & 70 & 0.7751 & 0.001251 & 52 & 4.3615 & 0.009508 \\
\hline Pretty unsatisfied & 212 & 2.4251 & 0.002932 & 100 & 9.6849 & 0.020292 \\
\hline Not unsatisfied, nor satisfied & 326 & 4.4679 & 0.004544 & 53 & 6.5142 & 0.017510 \\
\hline Pretty satisfied & 1286 & 23.6375 & 0.018333 & 185 & 31.2604 & 0.060829 \\
\hline Satisfied & 2131 & 42.1380 & 0.014151 & 227 & 31.2928 & 0.043082 \\
\hline Very satisfied & 1001 & 24.7668 & 0.017617 & 82 & 11.0726 & 0.029725 \\
\hline
\end{tabular}

about neighbourhood on individuals' assessment of their housing is inconclusive, with only a couple of coefficient being significant (i.e., crime problems in the neighbourhood brings individual dissatisfaction while the presence of green areas around the house causes more individual satisfaction). As already indicated by Lu (1999) earlier on, this may imply that individuals' assessment of housing takes into consideration the desirability of the neighbourhood as a whole, but the role of specific aspects of the neighbourhood in such assessments is not certain.

The last group of regressors is included to test for the importance of social comparisons (contextual effects only) on individual housing satisfaction. To begin with, it is intuitive to think that people compare themselves with what they see in other individuals in the neighbourhood and this justifies the "modal" (most visible) reference for ownership and public housing. For the former, results indicate that renting in a predominantly homeowners' neighbourhood significantly causes housing dissatisfaction confirming previous empirical findings in other happiness domains which postulate that better-off people impose a negative externality on their counterparts (Ferrer-i-Carbonell 2002b; Luttmer 2005; Vera-Toscano et al. 2006). This result is particularly interesting in a country like Spain where the percentage of homeowner is significantly high. ${ }^{6}$

Therefore, it does not seem to be the fact of being an owner vs. non-owner what causes satisfaction or dissatisfaction but the fact of being the renter surrounded by home-owners. In the same direction, being surrounded by public housing also causes dissatisfaction (weak significance). This result reflects once again that the type of neighbourhood affects one's satisfaction with her dwelling.

Lastly, we further include the difference between one's property value and the mean property value of the reference group (we assume that when asked, individuals tend to report the rough average property value of their neighbourhood rather than a modal or median value). Results indicate that the coefficients for these determinants are not significant. Opposite to what we observed for ownership, the property value of our peers does not seem to affect individuals' housing satisfaction.

\footnotetext{
${ }^{6}$ In particular, $79 \%$ of total household assets are made of housing and other real estate, $82 \%$ of households are home owners, almost $19 \%$ own a secondary residence, and $30 \%$ possess a secondary residence or other real estate properties. More strikingly, for the bottom $20 \%$ of households in the income distribution, $74 \%$ of them are owner occupiers and $18.5 \%$ have other real estate properties. The impact of house price fluctuations on expenditure will therefore affect most households significantly (Bover 2005).
} 
We end up our empirical specification studying the relevance of social capital, measured as informal contacts with neighbours (that is, daily or weekly contact to enjoy your leisure time, have a chat, go to the cinema or even go out for a drink) so as to accommodate for the intensity of these contextual effects. Surprisingly, higher social relations do not provide other things equal, higher level of individual housing satisfaction. Our understanding for this result is that while social contacts were pretty much valued in the old times, as Spanish society has got richer the importance of the informal social capital has significantly decrease to equal other developed economies where anonymity rules.

\section{Conclusions}

The purpose of this paper was to contribute further research on the conceptualization of individual's housing satisfaction, paying particular attention to the potential effect of social interactions (understood as external norms established by a given reference group). The study used the Survey on Living Conditions and Poverty in Andalucía (Spain) and an ordered probit model in its empirical analysis. To the extent that the results by and large confirm earlier findings reported in the literature, we believe this research significantly contributes the empirical literature on housing satisfaction.

The results of this study indicate that housing satisfaction is affected by an array of individual, housing and neighbourhood attributes. Nonetheless, it is also important to take into account the effect of social interactions. Results seem to be robust so as to confirm that our relevant others influence not only our objective behaviour (as shown by Ioannides and Zabel) but also our evaluation of it (subjective outcome).

Thus, individuals evaluate their housing situation taking into account not only whether they are owners or renters, but simultaneously assessing others' ownership status. In this sense, individuals' housing satisfaction is negatively affected by the fact of being a renter surrounded by owners, while owners do not feel more satisfied with their housing if being surrounded by renters. This result is particularly interesting in a country like Spain where the percentage of homeowner is significantly high reinforcing the solidly established norm of "home ownership". However, we find that while the property value is positively related to housing satisfaction, the property value of our peers does not seem to significantly affect individuals' housing satisfaction. This result may indicate that for existing owners, and given the high and increasing price of housing, this composite commodity is clearly an investment good and it is one's housing price what interests most.

This research has also shown that the type of place one lives in affect housing satisfaction as residents of private housing surrounded by public housing are less likely to feel satisfied with their housing. Surprisingly, higher social relations do not provide other things equal, higher level of individual housing satisfaction among dwellers failing the intensity of social interaction hypotheses.

These results are likely to have a great deal of policy implications. As for the USA case (Bajari et al. 2005) incentives for homeownership in the form of universal subsidies may be misguided (medium class...). It will be interesting to study the effects in Spain. Furthermore, the problem of new-entrants is that they are likely to be young people, with high permanent income, but low wealth accumulated (few time has passed), if the sunk-initialinvestment of buying is too big (it is increasing - accelerated), they are not able to compensate by public subsidies (tax reduction) their reduced capacity. Additional research is needed in both areas. 
Overall, we believe that the simultaneous inclusion of individuals, housing, neighbourhood and peers characteristics in people's utility function certainly enriches the complex housing satisfaction concept. Taking into account the importance of housing satisfaction on overall individual happiness (subjective well-being) is an important argument to justify this type of research.

Acknowledgements We are grateful to the Fundación Centro de Estudios Andaluces for their financial support through the project "Satisfacción con la Vivienda en Andalucía" (SOCH 2.05/009). Funding from the Department of Social Affairs of the Andalucian Regional Government to undertake the Survey is also acknowledged. Vera-Toscano wants to further acknowledge Junta de Andalucía for the support provided for this research through Averroes, and Ateca-Amestoy acknowledges Gobierno Vasco (BFI 05.225). All usual caveats apply.

\section{References}

Bajari, P., Benkard, C. L., \& Krainer, J. (2005). House prices and consumer welfare. Journal of Urban Economics, 58, 474-487.

Bover, O. (2004). The Spanish Survey of Household Finances (EFF): Description and methods of the 2002 wave, Occasional paper no. 0409, Banco de España.

Bover, O. (2005). Wealth effects on consumption: Microeconometric estimates from the Spanish Survey of Household Finances, Documento de Trabajo no. 0522, Banco de España.

Brock, W. A., \& Durlauf, S. N. (2003). Multinomial choice with social interactions, Mimeo.

Burgess, E. (1925). The growth of the city: An introduction to a research project. In R. E. Park, E. W. Burgess, \& R. D. McKenzie (Eds.), The city (pp. 47-62). Chicago: University of Chicago Press.

Campbell, A., Converse, P. E, \& Rodgers, W. L. (1976). The quality of American life: Perceptions, evaluations, and satisfactions. New York: Russell Sage Foundation.

Clark, A. E. (1997). Job satisfaction and gender: Why are women so happy at work? Labour Economics, $4(4), 341-372$.

Clark, A.E, \& Oswald A. J. (1994). Unhappiness and unemployment. Economic Journal, 104(424), 648-659.

Clark, A. (2003). Unemployment as a social norm: Psychological evidence from panel data. Journal of Labor Economics, 21, 323-351.

Di Pasquale, D., \& Glaeser, E. (1999). Incentives and social capital: Are homeowners better citizens? Journal of Urban Economics, 45, 354-384.

Díaz-Serrano, L. (2005). Housing satisfaction, homeownership and housing mobility: A panel data analysis for twelve EU countries. IZA DP NO, 2318, IZA Bonn.

Diener, E., \& Biswas-Diener, R. (2002). Will money increase subjective wellbeing? A literature review and guide to needed research. Social Indicators Research, 57, 119-169.

Falk, A., \& Knell, M. (2000). Choosing the Joneses: On the endogeneity of reference groups. Institute for Empirical Research in Economics, University of Zurich WP, No. 59.

Ferrer-i-Carbonell, A. (2002a). Subjective questions to measure welfare and well-being: A survey. Tinbergen Institute Discussion Paper 2002-020/3.

Ferrer-i-Carbonell (2002b). Income and Well-Being. An empirical analysis of the comparison income effect. Tinbergen Institute Discussion Paper 2002-019/3.

Ferrer-i-Carbonell, A., \& Frijters, P. (2004). How important is methodology for the estimates of the determinants of happiness? Economic Journal, 114, 641-659.

Foley, D. L. (1980). The sociology of housing. Annual Review of Sociology, 6, 457-478.

Frey, B. S., Benz, M., \& Stutzer, A. (2003). Introducing procedural utility: Not only what but also how matters. IEW working paper no. 129, University of Zurich.

Galster, G. C. (1987). Identifying the correlates of dwelling satisfaction: An empirical critique. Environment and Behavour, 19(5), 539-568.

Galster, G. C, \& Hesser, G. W. (1981). Residential satisfaction: Compositional and contextual correlates. Environment and Behavior, 13(6), 735-758.

Green, R. K, \& White, M. J (1997). Measuring the benefits of homeowning: Effects on children. Journal of Urban Economics, 41, 441-461.

Greene, W. (1990). Econometric analisis. New York: MacMillan. 
Instituto Nacional de Estadística (2005). Encuesta continua de presupuestos familiares. Base 1997. http:// www.ine.es/daco/daco43/metodo_ecpf.doc.

Ioannides, Y. M., \& Zabel, J. E. (2003). Neighbourhood effects and housing demand. Journal of Applied Econometrics, 18, 563-584.

Kahneman, D., Diener, E., \& Schwarz, N. (Eds.). (1999). Foundations of hedonic psychology: Scientific perspectives on enjoyment and suffering. NY: Russell Sage Foundation.

Lu, M. (1999). Determinants of residential satisfaction: Ordered logit vs. Regression Models. Growth and Change, 30, 264-287.

Luttmer, E. F. P. (2005). Neighbors as negatives: Relative earnings and well-being. Quarterly Journal of Economics, 120(3), 963-1002.

Manski, C. F. (1993). Identification of endogenous social effects: The reflection problem. The Review of Economic Studies, 60(3), 531-542.

Morris, E. W., \& Winter, M. (1975). A theory of family housing adjustment. Journal of Marriage and the Family, 37, 79-88.

Morris, E. W., \& Winter, M. (1978). Housing, family and society. New York: John Wiley and Sons.

Oswald, A. J. (1999). The housing market and Europe's unemployment: A non-technical paper, Mimeo, University of Warwick.

Putnam, R. (1993). Making democracy work. Civic traditions in modern Italy. Princeton: Princeton University Press.

Rohe, W. M., \& Basolo, V. (1997). Long-term effects of homeownership on the self-perceptions and social interaction of low-income persons. Environment and Behavior, 29(6), 793-184.

Rossi, P. H. (1955). Why families move. Glenco IL: The Free Press.

Sen, A. K. (1999). The possibility of social choice. American Economic Review, 89, 349-378.

Van Praag, B. M. S., Frijters, P., \& Ferrer-i-Carbonell, A. (2003). The anatomy of wellbeing. Journal of Economic Behavior and Organization, 51, 29-49.

Van Praag, B. M. S., \& Ferrer-i-Carbonell, A. (2004). Happiness quantified. A satisfaction calculus approach. Oxford University Press.

Vera Toscano, E., Ateca Amestoy, V., \& Serrano del Rosal, R. (2006). Building financial satisfaction. Social Indicators Research, 77, 211-243.

Veblen, T. (1899). The theory of leisure class. New York: Modern Library. 